Relato de Experiência

Revista Saúde.Com

ISSN 1809-0761

www.uesb.br/revista/rsc/ojs

Rev. Saúde.Com 2020; 16(1): 1761-1765

\title{
EXTENSÃO UNIVERSITÁRIA NA ODONTOLOGIA COMO UMA EXPERIÊNCIA EM SAÚDE
}

\section{UNIVERSITY EXTENSION IN DENTISTRY AS AN HEALTH EXPERIENCE}

\author{
André Rodrigo Justino da Silva \\ Universidade Federal de Campina Grande
}

\begin{abstract}
The university extension has the function of articulating teaching and research, in addition to bringing the university closer to the community. The objective of this study is to report the extension practice, in municipal day care centers, through a extension project of the Federal University of Campina Grande dentistry course. Activities were carried out in three public schools of children's education by dentistry academics and their teachers with 290 pre-school children, their parents and teachers, promoting oral health through play activities, talk wheels and questionnaires. Based on the actions, there were improvements in the brushing techniques of the children, as well as motivation to improve their habits and parents, however, it was noticed a high sugar consumption by the children. The teachers of the institutions showed little knowledge about oral health practices and their ways of approach, besides affirming lack of incentive coming from the higher organs to carry out activities on the subject in the school environment. There is a need to increase the incentive of the extension practice to improve the oral health conditions of children and their families, with special attention to public schools and pre-schools located in regions of low socioeconomic status.
\end{abstract}

Keywords: Community-Institutional Relations. Health Promotion.Dental Caries.

\section{Resumo}

A extensão universitária tem função de articular ensino e pesquisa, além de aproximar a universidade da comunidade. Desse modo, o objetivo deste estudo é relatar a prática extensionista, em creches municipais, através de um projeto de extensão do curso de odontologia da Universidade Federal de Campina Grande. Foram desenvolvidas atividades em três escolas públicas de ensino infantil por acadêmicos de odontologia e seus professores com 290 crianças em idade pré-escolar, seus pais e professores, promovendo saúde bucal através de atividades lúdicas, rodas de conversa e questionários. A partir das ações observaram-se melhorias nas técnicas de escovação das crianças, além de motivação para melhoria de hábitos delas e dos pais, entretanto percebeu-se alto consumo de açúcar pelas crianças. Os professores das instituições demonstraram pouco conhecimento sobre práticas de saúde bucal e suas formas de abordagem, além de afirmarem falta de incentivo proveniente dos órgãos superiores para realização de atividades sobre o tema no ambiente escolar. Portanto, há necessidade de aumento do incentivo da prática extensionista para melhoria das condições de saúde bucal de crianças e seus familiares, com atenção especial às escolas e pré-escolas públicas localizadas em regiões de baixo nível socioeconômico.

Palavras-chave: Relações comunidade-instituição. Promoção da saúde. Cárie dentária. 
Introdução

A extensão universitária, no que diz respeito às universidades públicas brasileiras teve seu conceito bastante modificado, passando por várias formas e diretrizes e resignificando sua relação com os outros âmbitos acadêmicos e com a comunidade na qual se insere. O marco da extensão universitária para a América latina aconteceu em 1918 na forma de um movimento estudantil de Córdoba-Argentina, que defendia uma extensão universitária comprometida com mudanças sociais e pensada sob olhar político pelos docentes e discentes, questionando o modelo de práticas pontuais e, muitas vezes dissociadas dos problemas locais reais ${ }^{1}$.

No fim da década de 30 , as práticas de extensão passaram por um período de grande efervescência no Brasil com foco na cultura, sob forma de salas de leitura e rádio para a difusão cultural, bem como na discussão e solução dos problemas sociais através de cursos e conferências $^{2}$. No que diz respeito à prática extensionista no curso de odontologia, esta se concentra no atendimento à saúde bucal da população através de ferramentas assistenciais e de prestação de serviços, tendo grande número de discentes e docentes envolvidos nessas atividades. Por outro lado, a universidade não objetiva ocupar espaços de políticas públicas, apesar de contribuir para isso ${ }^{3}$.

Sendo o maior foco de promoção de saúde, a cárie dentária é uma doença multifatorial que é modificada por fatores sociais, ambientais, genéticos e comportamentais ${ }^{4}$. Desse modo, sendo de etiologia complexa, os epidemiologistas enfrentam o desafio que é identificar potenciais causadores e determinantes da doença cárie para, a partir disso planejar medidas de saúde pública adequadas para controlar a doença e suas conseqüências ${ }^{5}$. Assim, a prevenção e promoção em saúde são essenciais para propagar conhecimento e mudanças de comportamento quanto aos hábitos corretos de higiene e de alimentação não-cariogênica6 .

Com isso, verifica-se a necessidade de experiências com a extensão para fortalecer a existência universitária e propagar novas formas de ensino e aprendizado para outras pessoas, bem como o presente trabalho se justifica. 0 presente trabalho objetiva relatar a prática extensionista, em creches municipais, através de um projeto de extensão do curso de odontologia da Universidade Federal de Campina Grande.

\section{Metodologia}

As atividades desenvolvidas durante 0 projeto de extensão "Construindo Sorrisos" foram executadas pelos acadêmicos e professores do curso de Odontologia da Universidade Federal de Campina Grande, em três escolas públicas de ensino infantil, abrangendo cerca de 290 crianças em idade préescolar; tendo como público-alvo tanto as crianças quanto seus pais e professores, de modo a promover saúde e informação para elas, tornarem seus responsáveis propagadores e reforçadores no cotidiano fora da esfera escolar e preparar os educadores para inserir práticas de saúde bucal na vida escolar.

Foram promovidas ações educativas com as crianças a respeito da dieta saudável e higiene bucal por meio de atividades lúdicas como teatro de fantoches, músicas, desenhos para colorir. Durante essas atividades foram apresentadas ainda as técnicas de escovação e promoveu-se a escovação supervisionada a partir de um condicionamento em sala de aula que acontecia com todos os alunos vestindo seus Equipamentos de Proteção Individual (EPI) na frente das crianças e apresentando cada um deles de forma lúdica.

Além disso, também se realizaram ações com os pais e professores por meio de rodas de conversa, oportunidade em que foram aplicados questionários de avaliação da dieta e higiene das crianças, elaborados pelos acadêmicos de odontologia sob supervisão dos professores orientadores. Aplicou-se também questionário de nivelamento sobre o conhecimento acerca de saúde bucal para os professores, havendo a troca de informações de modo a promover o esclarecimento acerca da saúde bucal das crianças. Foram entregues aos pais folders educativos com informações básicas para construção do conhecimento sobre saúde bucal neles, para assim transmitir às crianças.

\section{Resultados e discussões}

Os resultados foram obtidos durante a segunda vigência do projeto, de maio a dezembro do ano de 2016. De modo geral observaram-se melhorias nas técnicas de escovação usadas pelas crianças a partir de conversas com seus responsáveis, bem como mudanças positivas nos hábitos de higiene e 
alimentação das crianças após as atividades do projeto. As atividades executadas serviram para a motivação das mudanças nas práticas de higiene e alimentação das crianças, tanto dentro quanto fora do ambiente escolar.

Durante as rodas de conversa, percebeu-se que há um alto consumo açúcar pelas crianças, contribuindo para o desenvolvimento de cáries. Isso foi confirmado após a aplicação dos questionários de avaliação da dieta, nos quais se referiu principalmente uso de mamadeiras noturnas sem posterior escovação e grande consumo de açúcar na forma de doces e guloseimas, com frequência intermediária, porém com grandes intervalos de tempo.

Com relação aos professores das instituições envolvidas, observou-se deficiência de conhecimento sobre práticas de saúde bucal e suas formas de abordagem, além da afirmação da falta de incentivos vinda dos órgãos superiores para realização de atividades cotidianas e contínuas sobre o tema dentro do âmbito escolar.

Quantos aos alunos extensionistas, a prática da futura profissão nessa esfera da graduação foi referida como enriquecedora e serviu como inspiração para o retorno ao ambiente universitário para que nele fossem associadas às experiências vividas as informações teorias, além da troca de vivências com seus colegas.

O período escolar é importante para a promoção de saúde ser trabalhada através de ações focadas em prevenção de doenças e fortalecimento dos fatores de proteção. Além disso, a escola possui um papel pedagógico específico, mas também uma função de transformação da sociedade por meio do exercício da cidadania e acesso às oportunidades de aprendizagem e desenvolvimento, justificando assim a realidade de ações no ambiente escolar que ponham em prática as propostas de promoção de saúde ${ }^{7}$.

A idade pré-escolar, ou seja, a primeira infância, para a odontologia é um grupo prioritário de trabalho pelo fato desse grupo apresentar alto risco à doença cárie, como afirmado no levantamento epidemiológico em saúde bucal no Brasil realizado em 2004: os valores de prevalência da cárie precoce na infância apontaram-na como problema de saúde pública com $26,85 \%$ das crianças de 18 a 36 meses e $59,37 \%$ das crianças de cinco anos sendo portadoras de cárie dentária ${ }^{8}$. Por isso a importância de projetos de extensão voltados para esse grupo etário, como o descrito no presente trabalho.

Na realização de ações educativas para préescolares é necessário que o dentista saiba mais do que apenas usar seu conhecimento técnico, mas também atuar como agente de saúde com embasamento em ciências sociais e psicologia para envolver pais e professores tornando-os agentes multiplicadores. $O$ engajamento destes é essencial para que o que foi programado tenha seu objetivo atingido com êxito. Portanto, disseminar o saber é imprescindível, apesar de ser necessário ter em mente que o dentista não é portador da verdade absoluta e que ela se constrói a partir do diálogo e do intercâmbio de experiências para assim associar o saber científico ao saber popular ${ }^{9}$.

Professores e cuidadores também foram alvos do presente estudo, pois são personagens fundamentais para as ações, conhecem muito bem as crianças e dão grande suporte na sua abordagem. Por isso que os cirurgiões-dentistas percebem cada vez mais a necessidade de praticar a interdisciplinaridade trabalhando em conjunto com profissionais da educação, de modo a contribuir para as condições de abordagem e atendimento tornando estes uma experiência melhor para a criança, que é o alvo principal e, se bem abordada reflete-se em uma população mais consciente e informada sobre a importância de ser prevenir, antes mesmo do tratamento ${ }^{10-12}$.

Por outro lado, aos acadêmicos que participam de projetos de extensão como este é ofertada aprendizagem na abordagem de educação em saúde, o incentivo no desenvolvimento de pesquisas voltadas à saúde e a aproximação entre as esferas comunidade e universidade. Assim, para o futuro profissional é dada a oportunidade do desenvolvimento de sensibilidade social e humanitária advindos da participação ativa junto à população. Atualmente, é necessário que aconteça mudança de cenários nas escolas, passando de um ambiente puramente educativo para um ambiente também de conscientização da realidade sanitária e social ${ }^{13,14}$

Os efeitos dos fatores socioeconômicos no consumo de açúcar têm sido relatados por alguns estudos. Autores em uma pesquisa realizada em duas pré-escolas públicas de Bauru, São Paulo envolvendo crianças de 4 a 6 anos verificaram que a maioria das crianças envolvidas apontou preferência por uma solução mais doce, sem 
variação referente a idade e sexo. Com relação aos grupos socioeconômicos, os pertencentes ao grupo menos favorecido mostraram tanto maior preferência por açúcar quanto prevalência de cárie mais elevada ${ }^{15}$.

Essa preferência por açúcar é principalmente influenciada por uma maior exposição das crianças a ele, decorrente de uma oferta aumentada por associação à urbanização $^{16}$. Há associação estatisticamente significativa entre a presença de cárie dentária e as seguintes variáveis econômicas: renda familiar, grau de instrução do pai e da mãe, habitação e classe socioeconômica ${ }^{17}$.

Em um estudo realizado em Recife, Pernambuco observa-se que crianças das escolas públicas municipais tiveram prevalência de cárie alta $(47,00 \%)$, além disso, entre as crianças que apresentavam cárie, uma pequena parcela $(13,60 \%)$ já tinha passado por algum tratamento curativo $^{18}$. Desse modo, os programas de educação em saúde devem se adequar aos aspectos de escolaridades da população que pretende ser obrigatória e se adequar à sua linguagem. Além disso, na apresentação das alternativas viáveis para a melhoria da saúde deve ser levada em conta a condição econômica do público com ações coletivas e que abrangem o máximo de pessoas.

Dados apontam que a forma que as pessoas percebem os problemas bucais geralmente está associada à dor, bem como cavitação no dente no caso de cárie dentária. Assim, é necessário o esclarecimento da população sobre a complexidade que envolve o processo saúdedoença bucal, focando que a doença cárie dentária tem seu início real bem antes dos sinais visíveis e/ou sintomas, de modo que há a possibilidade de tratamento precoce para controle dos prováveis problemas que podem estar envolvidos. Com isso, futuros tratamentos restauradores e reabilitadores poderiam ser evitados ${ }^{19}$.

Como formas de abordagem da promoção de saúde para crianças existem fortes evidências, obtidas a partir de estudos que avaliaram aspectos comportamentais e o grau de aprendizagem após a intervenção, que apontam a eficácia de jogos de computador e dinâmicas na abordagem de educação em saúde bucal, hábitos alimentares saudáveis, prevenção de doenças e o manejo de alguma condição já instalada. Além disso, jogos de tabuleiros e de cartas são igualmente significantes, pois estimulam o aprendizado de forma prazerosa, relacionando o lúdico com a realidade e aproximando o coletivo entre $\mathrm{si}^{20}$. Por outro lado é necessário ter em mente que somente a intervenção educativa baseada em saberes instituídos não é suficiente para promover mudanças concretas nas práticas do público-alvo, sendo assim necessário o incentivo para a mudança de comportamento, já que há diferenças entre a realidade de vida de quem está na posição de promotor de saúde bucal e quem é seu sujeito ${ }^{21}$.

Diante do exposto observa- se que um projeto de extensão universitária é essencial para a formação de cirurgiões-dentistas e, sobretudo, para melhoria das condições de saúde bucal de crianças e suas famílias.Além disso, as escolas e pré-escolas públicas localizadas em regiões de baixo nível socioeconômico devem ser vistas como urgência para promoção e intervenção em saúde para assim oferecer-se atenção à comunidade como um todo.

\section{Referências:}

1. Rocha RMG. A Construção do Conceito de Extensão universitária na America Latina. In. FARIA,Doris Santos de (org). Construção Conceitual da Extensão na AmericaLatina. Brasília. Editora UNB. 2001.

2. Jezine EM. Multiversidade e Extensão Universitária In. FARIA,Doris Santos de (org). Construção Conceitual da Extensão na America Latina. Brasilia. Editora UNB, 2001.

3. Fonseca AS, Lorenzo HCD. Breve perfil das atividades de extensão nas unidades da UNESP, campus de Araraquara: um enfoque na transferência de tecnologia e conhecimento. RCE, São Paulo, 1 (2), p. 112-129, 2004.

4. Ditmyer $M$, Dounis $G$, Mobley C, Schwarz E. A case-control study of determinants for high and low dental caries prevalence in nevada youth. BMC Oral Health, 2010.

5. Peres MA, Barros AJ, Peres KG, Araújo $\mathrm{CL}$, Menezes AM. Life course dental caries determinants and predictors in children aged 12 years: a population-based birth cohort. CommunityDent Oral Epidemiol. 37: 123-133. 2009.

6. Corrêa MSNP. Odontopediatria na 1a. Infância. 29. ed. São Paulo: Santos, 2005.

7. Brasil. Ministério da Saúde. A promoção da saúde no contexto escolar. Rev Saúde Públ, 36 (2), p. 533-535, 2002. 
8. Brasil. Ministério da Saúde. Projeto SB Brasil 2003. Condições de saúde bucal da população brasileira 2002-2003. Resultados principais. Brasília, DF, 2004.

9. Santos KT, Garbin AJI, Garbin CAS. Saúde bucal nas escolas: relato de experiência. RevCiênc Ext. 8 (1), p. 161-169, 2012.

10. Toassi RFC, Petry PC. Motivação no controle do biofilme dental e sangramento gengival em escolares. Rev Saúde Públ, 36 (5): 634-7, 2002.

11. Aquilante AG, Almeida BS, Martins de Castro RF, Xavier CRG, Sales Peres SHC, Bastos JRM. A importância da educação em saúde bucal para pré-escolares. Rev Odontol UNESP, 32 (1), p. 3945, 2003.

12. Alves MU, Volschan BCG, Haas NAT. Educação em saúde bucal: sensibilização dos pais de crianças atendidas na clínica integrada de

duas Universidades privadas. PesqBrasOdontopedClinIntegr, 4 (1), p. 47-51, 2004.

13. Campos FE, Belisário AS. O programa da Saúde da Família e os desafios para a formação profissional e a educação continuada. Interface Comunic, Saúde, Educ, 5 (9), p. 133-142, 2001.

14. Santos KT, Gonçalves CM, Carvalho RB. O PET-Saúde como instrumento de re-orientação do ensino em odontologia: a experiência da Universidade Federal do Espírito Santo. Rev ABENO, 11 (1), p. 96-97, 2011.

15. Tomita NE, Nadanovsky P, Vieira ALF, Lopes ES. Preferências por alimentos doces e cárie dentária em pré-escolares. Rev SaúdePúbl, 33 (6): 543-46, 1999.

16. Jamel HA, Sheiham A, Cowell CR, Watt RG. Taste preference for sweetness in urban and rural population in Iraq. J Dent Res; 75: 1879-84, 1996.

17. Meneghim MC, Kozlowski FC, Pereira AC, Ambrosano GMB, Meneghim ZMAP. Classificação socioeconômica e sua discussão em relação à prevalência de cárie e fluorose dentária. Ciênc Saúde Colet, 12 (2): 523-529, 2007.

18. Feitosa S, Colares V. Prevalência de cárie dentária em pré-escolares da rede pública de Recife, Pernambuco, Brasil, aos quatro anos de idade. Cad Saúde Públ, Rio de Janeiro, 20 (2): 604-609, mar- abr, 2004.

19. Unfer B, Saliba O. Avaliação do conhecimento popular e práticas cotidianas em saúde bucal. Rev Saúde Públ, 34 (2): 190-5, 2000.
20. Coscrato G, Pina JC, Mello DF. Utilização de atividades lúdicas na educação em saúde: uma revisão integrativa da literatura. Acta Paul Enferm. 2010; 23 (2): 257-63.

21. Gazzinelli MF, Gazzinelli A, Reis DC, Penna CMM. Educação em saúde: conhecimentos, representações sociais e experiências da doença. Cad Saúde Públ, Rio de Janeiro, 21 (1): 200-206, jan-fev, 2005.

\section{Endereço para Correspondência}

Universidade Federal de Campina Grande- UFCG

R. Aprígio Veloso, 882 - Universitário,

Campina Grande - PB

CEP.:58428-830

e-mail: a.rodrigo2010@hotmail.com

Recebido em 22/11/2019

Aprovado em 13/04/2020

Publicado em 30/03/2020 